\title{
Перспективные конструкции электро-оптических модуляторов на кремнии
}

\author{
О.В. Наумова, Б.И. Фомин, Д.В. Щеглов \\ Институт физики полупроводников им. А.В. Ржанова СО РАН, \\ Новосибирск, 630090, пр. Ак. Лаврентьева, 13 \\ тел:+7 (383) 330-6768, факс:+7 (383) 333-2771, эл. почта: nauтоva@isp.nsc.ru
}

DOI 10.34077/RCSP2019-85

Электро-оптические модуляторы (ЭОМ) являются обязательным, ключевым компонентом систем передачи информации с использованием светового излучения. Большие потери при передаче электрических сигналов на частотах $\mathrm{f} \geq 10$ ГГц посредством обычной металлической разводки и большая скоростью передачи данных по оптоволокну (теоретический предел 1014бит/с) определяют актуальность разработок приборов данного типа.

Мотивация изготовления ЭОМ на кремнии обусловлена: 1) физическими свойствами системы $\mathrm{Si} / \mathrm{SiO} 2,2)$ возможностью изготовления волноводов на основе пленок кремния-на-изоляторе и 3) возможностью использования хорошо разработанной КМОП-технологии. Это, в свою очередь: 1) упрощают процесс интеграции для кремниевой фотоники (включая возможность формирования гибридных устройств со встраиванием разных материалов в КНИ-волновод), 2) обеспечивают недорогую платформу для промышленного производства систем оптической связи и 3) дает возможность изготовления оптико-электрических интегральных схем (сетей) чипового масштаба $[1,2]$.

Самый распространенный метод модуляции световой волны, используемый в настоящее время в кремниевых устройствах, основан на эффекте дисперсии свободных носителей заряда [2, 3]. Известными методами изменения концентрации свободных носителей заряда являются их инжекция, обогащение или истощение (обеднение) в p-n-диодных или емкостных МОП-структурах. Поэтому в последние десятилетия велась интенсивная разработка кремниевых ЭОМ с разными конструктивнотехнологическими решениями.

В данной работе представлен анализ конструктивно-технологических особенностей современных кремниевых модуляторов на основе p-n-диодов в инжекции, обеднении и емкостных МОП-структур. Показаны наиболее перспективные конструкции.

Работа выполнена при поддержке проекта RFMEFI58117X0026.

\section{Лumepamypa}

[1] G. T. Reed, G. Z. Mashanovich, F. Y. Gardes, et al. // Nanophotonics. 2014. Vol. 3, No 4-5. P. 229-245.

[2] P. Dong, S. Chandrasekhar. Photonic integration. In: Enabling Technologies for High Spectralefficiency Coherent Optical Communication Networks. Ed. By X. Zhou and C. Xie. Hoboken, New Jersey: John Wiley@Sons. Inc. 2016. P.448-472.

[3] Reed G. T. Silicon Photonics. An Introduction / G.T. Reed, A. P. Knights . - Chichester : John Wiley \& Sons, 2004. $276 \mathrm{p}$. 